Article

\title{
Faecal Microbial Markers and Psychobiological Disorders in Subjects with Morbid Obesity. A Cross-Sectional Study
}

\author{
Per G Farup ${ }^{1,2, *(1)}$ and Jørgen Valeur ${ }^{3}(\mathbb{D}$ \\ 1 Department of Research, Innlandet Hospital Trust, PB 104, N-2381 Brumunddal, Norway \\ 2 Unit for Applied Clinical Research, Department of Clinical and Molecular Medicine, Faculty of Medicine \\ and Health Sciences, Norwegian University of Science and Technology, N-7491 Trondheim, Norway \\ 3 Unger-Vetlesen Institute, Lovisenberg Diaconal Hospital, N-0440 Oslo, Norway; Jorgen.Valeur@lds.no \\ * Correspondence: per.farup@ntnu.no; Tel.: +47-94-818-603; Fax: +47-61-157-437
}

Received: 30 July 2018; Accepted: 22 September 2018; Published: 27 September 2018

\begin{abstract}
Morbidly obese subjects have a high prevalence of comorbidity and gut microbial dysbiosis, and are thus suitable for the study of gut-brain interactions. The aim was to study the associations between the faecal microbiota's composition and function and psychobiological comorbidity in subjects with BMI $>40 \mathrm{~kg} / \mathrm{m}^{2}$ or $>35 \mathrm{~kg} / \mathrm{m}^{2}$ with obesity-related complications. The faecal microbiota was assessed with GA-Map dysbiosis test TM (Genetic Analysis, Oslo Norway) and reported as dysbiosis (yes/no) and degree of dysbiosis, and the relative abundance of 39 bacteria. The microbiota's function was assessed by measuring the absolute and relative amount of faecal short chain fatty acids. Associations were made with well-being, mental distress, fatigue, food intolerance, musculoskeletal pain, irritable bowel syndrome, and degree of abdominal complaints. One hundred and two subjects were included. The results confirmed the high prevalence of comorbidity and dysbiosis $(62 / 102 ; 61 \%)$ and showed a high prevalence of significant associations $(41 / 427 ; 10 \%)$ between the microbiota's composition and function and the psychobiological disorders. The abundant, but in part divergent, associations supported the close gut-brain interaction but revealed no clear-cut and straightforward communication pathways. On the contrary, the study illustrates the complexity of gut-brain interactions.
\end{abstract}

Keywords: gut-brain axis; faecal microbiota; faecal short chain fatty acids; morbid obesity; psychobiological disorders; well-being; mental distress; irritable bowel syndrome

\section{Introduction}

Obesity is a worldwide health problem that has nearly tripled since 1975 and it affects $13 \%$ of the adult population. It is associated with a wide range of comorbidities, such as cardiovascular diseases, diabetes, musculoskeletal disorders, cancer, and psychobiological disorders, and an increased risk of death [1].

Faecal dysbiosis has been defined as an imbalance in the faecal microbiota. It is common in subjects with morbid obesity $(\mathrm{MO})$ and it has been mentioned as a causal factor for obesity and the comorbidities such as insulin resistance, glucose intolerance and diabetes type II, as well as psychiatric and functional disorders [2-6].

The gut-brain axis is a bidirectional link between the gut and the brain and of importance for various psychobiological disorders, such as anxiety, depression, fatigue, stress reactions, pain syndromes, and functional gastrointestinal disorders [7-9]. The absolute or relative amounts of the gut microbes per se and the microbes' metabolic products are possible mediators of the gut-brain 
effects. Faecal short chain fatty acids (SCFA), which are products of bacterial fermentation, have been proposed as mediators of the health-related effects [10,11].

The primary aim of this study in subjects with morbid obesity was to explore associations between the faecal microbiota's composition and metabolic products and a selection of psychobiological disorders. The secondary aims were to compare the subjects' microbiota with that of healthy reference populations. The high prevalence of psychobiological disorders and faecal dysbiosis in subjects with morbid obesity makes this group of special interest for the study of gut-brain interactions.

\section{Materials and Methods}

\subsection{Study Design}

A cross-sectional study in subjects with morbid obesity. The microbial composition was analysed with a commercially available test, and the results were compared with the test producer's reference population [12]. The faecal SCFA were compared with the faecal samples from healthy volunteers, as previously published [13].

\subsection{Participants}

Consecutive subjects aged 18-65 years with MO (defined as BMI $>40$ or $>35 \mathrm{~kg} / \mathrm{m}^{2}$ with morbidity related comorbidity), referred to the Unit for Obesity at Innlandet Hospital Trust-Gjøvik, Norway in the period from December 2012 to September 2014 were eligible for the study. Subjects with organic gastrointestinal disorders, major psychiatric disorders, severe not obesity-related somatic disorders, alcohol or drug addiction, and previous obesity surgery or other major abdominal surgery were excluded.

The healthy volunteers were healthcare workers and students from Haukeland University Hospital, Bergen, Norway who considered themselves healthy.

\subsection{Accomplishment}

In all morbidly obese subjects, a medical history was taken, a physical examination was performed, and blood and faecal samples were collected. The information was collected on paper-based questionnaires that were filled in by the doctors, the study nurse, and the participants. Other examinations were performed at the doctors' discretion. Except for some demographic data, no information was available about the healthy volunteers.

\subsection{Variables}

\subsubsection{Participants' Characteristics}

- Gender, age (years), height (m), weight $(\mathrm{kg})$, BMI $\left(\mathrm{kg} / \mathrm{m}^{2}\right)$, coffee (cups/day), smoking (daily, previously, never), and previous and present diseases.

- Physical activity was the sum of two questions: Easy activity (not sweaty/breathless): None; $<1 \mathrm{~h} ; 1-2 \mathrm{~h} ;>3 \mathrm{~h} /$ week (score 0-3). Strenuous activity (sweaty/breathless): none; $<1 \mathrm{~h} ; 1-2 \mathrm{~h}$; $>3 \mathrm{~h} /$ week (score $0,3,4,5)$. Sum score physical activity $0-8$.

- Use of Metformin and other drugs (Yes/No)

- Use of Non-Nutritive Sweeteners (NNS). One unit of NNS was defined as $100 \mathrm{~mL}$ NNS-containing beverage or two NNS tablets/teaspoons for use in tea or coffee. A validated food frequency questionnaire that is based on the official Norwegian food composition table was used for the calculation [14].

\subsubsection{Psychobiological Disorders}

- WHO-5 Well-being index (score 0-100; scores $\leq 50$ indicate low mood and scores $\leq 28$ indicate likely depression) [15] 
- Hopkins symptom checklist 10, (score 1-4; scores $\geq 1.85$ indicate mental distress) [16]

- Fatigue (Score 9-63; scores $\geq 36$ indicate further evaluation). The diagnose was based on a validated Norwegian translation of the Fatigue Severity Scale [17].

- Musculoskeletal pain from six parts of the body (score 0-12).

- Food intolerance (yes/no) as reported by the participants.

- Irritable Bowel Syndrome (IBS) (yes/no) was diagnosed with a validated Norwegian translation of the Rome III criteria [18].

- Abdominal complaints were scored with IBS Severity Score system (IBS-SSS) (score 0-500) [19]. All of the subjects with abdominal complaints, and not only those with IBS, filled in the questionnaire.

\subsubsection{Faecal Microbiota}

The CE marked GA-map ${ }^{\mathrm{TM}}$ Dysbiosis Test (Genetic Analysis AS, Oslo, Norway) was used for the analyses of the faecal microbiota [12]. The test has a US (Patent No. 9243297) and a European patent (Patent No. 2652145) for its technology governing the oligonucleotide probe set and methods of microbiota profiling [20]. It uses 54 oligonucleotide probes targeting the $16 \mathrm{~S}$ rRNA gene at different bacterial taxonomic levels.

The overall result is given as the Dysbiosis Index (DI) with scores 1 to 5; values above 2 indicate a microbiota profile that differs from the producer's reference population (i.e., dysbiosis). The results are also given as the relative abundance compared to a reference population (score -3 to 3) of 39 bacteria at different taxonomic levels (Actinobacteria, Actinomycetales, Bifidobacterium spp., Alistipes, Alistipes onderdonkii, Bacteroides fragilis, Bacteroides spp. \& Prevotella spp., Bacteroides stercoris, Bacteroides zoogleoformans, Parabacteroides johnsonii, Parabacteroides spp., Firmicutes, Bacilli, Catenibacterium mitsuoka, Clostridi a, Clostridium sp., Dialister invisus, Dialister invisus \& Megasphaera micronuciformis, Dorea spp., Eubacterium biforme, Eubacterium hallii, Eubacterium rectale, Eubacterium siraeum, Faecalibacterium prausnitzii, Lachnospiraceae, Lactobacillus ruminis \& Pediococcus acidilactic, Lactobacillus spp., Phascolarctobacterium sp., Ruminococcus albus \& R. bromii, Ruminococcus gnavus, Streptococcus agalactiae \& Eubacterium rectale, Streptococcus salivarius ssp. thermophiles \& S. sanguinis, Streptococcus salivarius ssp. Thermophilus, Streptococcus spp., Veillonella spp., Proteobacteria, Shigella spp. \& Escherichia spp., Mycoplasma hominis, and Akkermanasia muciniphilia). The test is a commercial and patented product-hence the dysbiosis scores are the producer's secret.

In addition, an Alternative Dysbiosis Index (ADI) that is based on the relative abundance of the bacteria Alistipes, Proteobacteria and Shigella spp. \& Escherichia spp., and the relative scarcity of Bacteroides fragilis, Ruminococcus gnavus, Bacteroides spp. \& Prevotella spp., and Dialister invisus was calculated. The ADI has been claimed to separate the favourable dysbiosis (positive scores) from the unfavourable one (negative scores) [21].

\subsubsection{Faecal Short Chain Fatty Acids}

The subjects with morbid obesity collected the faecal material at home in kits that were provided by the producer of the microbial test and stored it at room temperature for maximum five days before freezing at minus $70{ }^{\circ} \mathrm{C}$ [12].

Distilled water containing $3 \mathrm{mmol} / \mathrm{L}$ of 2-ethylbutyric acid (as internal standard) and $0.5 \mathrm{mmol} / \mathrm{L}$ of $\mathrm{H}_{2} \mathrm{SO}_{4}$ was added to $0.5 \mathrm{~g}$ of the faecal content and homogenized. According to the method of Zijlstra et al. as modified by Høverstad et al. $2.5 \mathrm{~mL}$ of the homogenate was vacuum distilled [22,23]. The distillate was analysed with gas chromatography (Agilent 7890 A; Agilent, CA, USA) using a capillary column (serial no. USE400345H, Agilent J\&W GC columns; Agilent, CA, USA) and quantified while using internal standardisation. Flame ionisation detection was employed. The total amount of SCFA and the total and relative amount of acetic, propionic, n-butyric, i-butyric, n-valeric, i-valeric, $\mathrm{n}$-caproic, and $\mathrm{i}$-caproic acids expressed in $\mathrm{mmol} / \mathrm{kg}$ wet weight and proportion (percentage) were measured and reported. 
The following variables were also calculated:

- Index A (saccharolytic fermentation), which was the concentration of acetic minus propionate minus butyrate divided by the total amount of SCFAs [24].

- Index B (proteolytic fermentation), which was the sum of concentrations of isobutyrate and isovalerate [24].

- The ratio "Propionic acid/Butyric acid". A high ratio has been proposed as unfavourable [25].

In principle, the analyses of SCFA were performed with identical methods in the subjects with morbid obesity and the healthy volunteers. However, since the analyses were performed in different laboratories and with slightly different preanalytical handling of the samples, only the relative amounts of the SCFA were compared between the groups to avoid bias in the measuring of the total amounts of SCFA.

\subsection{Statistics}

Student $t$-test was used for comparisons between groups, Wilcoxon sign-rank test for comparisons with a reference standard, and linear and logistic regression analyses for the study of associations. In each analysis, all of the cases with data on the relevant variables were included ("available case analysis"). $p$-values $<0.05$ were judged as being statistically significant. The analyses were performed with IBM SPSS Statistics for Windows, Version 25.0. Armonk, NY, USA: IBM Corp.

\subsection{Ethics}

The study was approved by the Norwegian Regional Committees for Medical and Health Research Ethics, (reference numbers 2012/966 and 030.08) and was performed in accordance with the Declaration of Helsinki. All the participants gave written informed consent before inclusion.

\section{Results}

\subsection{Subject Characteristics}

Out of 350 consecutive subjects with morbid obesity, 111 were excluded because the study nurse was unavailable, and 80 refused participation. Out of 159 subjects included in the study, 17 were erroneously included or non-compliant and $40 \mathrm{did}$ not provide faecal samples. Table 1 gives the characteristics of the 102 subjects that were included in this study.

Table 1. Subject characteristics.

\begin{tabular}{|c|c|c|}
\hline Subject Characteristics & $\begin{array}{c}\text { Number (\%) } \\
\text { Mean and/or Median }\end{array}$ & SD and/or Range \\
\hline Gender (male/female) & $15(14.7 \%) / 87(85.3)$ & \\
\hline Age (years) & 44.2 & 8.6 \\
\hline Height $(\mathrm{cm})$ & 170 & 7.8 \\
\hline Weight (kg) & 120.8 & 16.1 \\
\hline $\mathrm{BMI}\left(\mathrm{kg} / \mathrm{m}^{2}\right)$ & 41.8 & 3.6 \\
\hline Coffee (cups/day) & 3.2 & 2.5 \\
\hline Smoking (daily/previously/never) & $14(13.7 \%) / 46(45.1 \%) / 42(41.2 \%)$ & \\
\hline Physical activity $(0-8)$ & 4.5 & 2.3 \\
\hline Diabetes (yes/no) & $23(23.2 \%) / 76(76.8 \%)$ & \\
\hline Metformin use (yes/no) & $16(18.0 \%) / 73(82.0 \%)$ & \\
\hline Non-nutritive sweeteners (units *) & 7.5 (median 3.3) & $10.1(0-43)$ \\
\hline WHO-5 (0-100) & 60.4 (median 60) & $16(12-92)$ \\
\hline HSCL-10 (1-4) & 1.58 (median 1.4 ) & $0.54(1.0-3.2)$ \\
\hline HSCL-10 Mental distress (yes/no) & $26(26.5 \%) / 72(73.5 \%)$ & \\
\hline Fatigue $(6-63)$ & 35.9 & 14.8 \\
\hline Musculoskeletal pain (0-12) & 4.4 & 2.9 \\
\hline Food intolerance (Yes/No) & $55(55.6 \%) / 44(44.4 \%)$ & \\
\hline IBS (Yes/No) & $27(27 \%) / 73(73 \%)$ & \\
\hline IBS Severity scoring system $(0-500)$ & 103 & $0-389$ \\
\hline
\end{tabular}

* One unit $=100 \mathrm{~mL}$ beverage with non-nutritive sweeteners or 2 tablets/teaspoons for coffee of tea. WHO-5: WHO Well-being index. HSCL-10: Hopkin Symptom Check List 10. IBS: Irritable Bowel Syndrome. 
The healthy volunteers that were used for comparisons of the SCFA were four men and eleven women with a mean age of 32.1 years (range 22-68) and BMI 23.7 (range 20.1-27.8 kg/m²).

\subsection{Dysbiosis Test}

Dysbiosis [Dysbiosis Index (DI) > 2] was present in 62/102 (61\%). The mean DI and Alternative Dysbiosis Index (ADI) scores were 2.8 (1.3) and -0.4 (2.6), respectively. When compared with producer's reference population [12], the relative amount of 22 bacteria were significantly elevated ( $p$-values $<0.05$, of which 12 bacteria with $p<0.001$ ) and the relative amount of 10 bacteria was significantly reduced ( $p$-values $<0.05$, of which 5 bacteria with $p<0.001$ ) The most marked deviations from the reference population were: Bacteroides spp. \& Prevotella spp.: Score $1.59(1.27)(p<0.001)$. Bacteroides fragilis: Score 0.54 (0.89) $(p<0.001)$. Bacteroides stercoris: Score $0.44(0.74)(p<0.001)$. Eubacterium hallii: Score $-0.54(0.54)(p<0.001)$. Faecalibacterium prausnitzii: $-0.49(0.71)(p<0.001)$.

\subsection{Short Chain Fatty Acids}

Total amount of SCFA was 35.99 (SD 21.24) $\mathrm{mmol} / \mathrm{kg}$ wet weight. Table 2 gives the results in the subjects with morbid obesity and the healthy volunteers with comparisons between the relative amounts of SCFA in the two groups.

Table 2. Short chain fatty acids (SCFA) in subjects with morbid obesity and healthy volunteers. The results are given as mean (SD).

\begin{tabular}{|c|c|c|c|c|}
\hline \multirow{2}{*}{ SCFA } & \multicolumn{2}{|c|}{ Subjects with Morbid Obesity } & \multirow{2}{*}{$\begin{array}{l}\text { Healthy Volunteers } \\
\text { Relative Amount (\%) }\end{array}$} & \multirow{2}{*}{$\begin{array}{c}\text { MO vs. HV } \\
\text { Relative Amounts } \\
p \text {-Value }\end{array}$} \\
\hline & $\begin{array}{c}\text { mmol/kg } \\
\text { Wet Weight }\end{array}$ & Relative Amount (\%) & & \\
\hline SCFA total & $35.99(21.24)$ & & & \\
\hline Acetic acid & $19.57(10.72)$ & $55.1(6.4)$ & $76.9(9.6)$ & $<0.001$ \\
\hline Propionic acid & $6.25(4.16)$ & $17.3(4.4)$ & $8.5(3.7)$ & $<0.001$ \\
\hline Iso-butyric acid & $0.72(0.61)$ & $2.1(0.9)$ & $1.4(0.7)$ & 0.006 \\
\hline Butyric acid & $7.13(5.28)$ & $19.2(5.3)$ & $9.5(4.6)$ & $<0.001$ \\
\hline Iso-valeric acid & $1.05(0.93)$ & $3.0(1.5)$ & $2.0(1.2)$ & 0.017 \\
\hline Valeric acid & $0.96(0.84)$ & $2.6(1.2)$ & $1.3(0.8)$ & $<0.001$ \\
\hline Iso-capronic acid & $0.00(0.01)$ & $0.0(0.0)$ & $0.0(0.0)$ & 0.163 \\
\hline Capronic acid & $0.29(0.51)$ & $0.7(1.0)$ & $0.4(0.5)$ & 0.187 \\
\hline Index A & $0.19(0.11)$ & & & \\
\hline Index B & $1.77(1.53)$ & & & \\
\hline Pro/But ratio & $1.01(0.53)$ & $1.01(0.53)$ & $1.0(0.4)$ & 0.864 \\
\hline
\end{tabular}

SCFA: Short chain fatty acids. MO: Subjects with morbid obesity. HV: Healthy volunteers. Pro/But ratio: The ratio Propionic acid/Butyric acid.

\subsection{Associations between the Psychobiological Disorders and the Microbial Markers}

Out of 427 analysed associations between the faecal microbiota and the psychobiological disorders, $41(10 \%)$ were statistically significant. Table 3 gives all of the statistically significant associations between the psychological disorders and the microbiota, and Table 4 provides all of the statistically significant associations between the functional somatic disorders and the microbiota. 
Table 3. The significant associations between the psychological disorders and the faecal microbiota and SCFA. Regression analyses with the psychological variables as dependent variables.

\begin{tabular}{|c|c|c|c|c|c|c|}
\hline \multirow{2}{*}{ Microbiota } & \multicolumn{2}{|c|}{ WHO-5 } & \multicolumn{2}{|c|}{ HSC-10 } & \multicolumn{2}{|c|}{ Fatigue } \\
\hline & B; $p$-Value * & B; $p$-Value $\uparrow$ & B; $p$-Value * & B; $p$-Value $T$ & B; $p$-Value * & B; $p$-Value $\mathrm{T}$ \\
\hline Dysbiosis Index & $-2.86 ; 0.024$ & & & & & \\
\hline Alistipes & & & & & $-5.42 ; 0.022$ & \\
\hline $\begin{array}{l}\text { Bacteroides spp. \& } \\
\text { Prevotella spp. }\end{array}$ & $-3.43 ; 0.010$ & & & & $2.84 ; 0.021$ & \\
\hline Dorea spp. & $12.18 ; 0.014$ & $11.44 ; 0.016$ & & & & \\
\hline $\begin{array}{l}\text { Faecalibacterium } \\
\text { prausnitzii }\end{array}$ & $6.37 ; 0.007$ & $5.65 ; 0.013$ & $-0.205 ; 0.011$ & $-0.191 ; 0.015$ & & \\
\hline Phascolarctobacterium sp. & & & & & $-6.77 ; 0.005$ & $-5.94 ; 0.009$ \\
\hline SCFA total & $-0.179 ; 0.019$ & & & & & \\
\hline Acetic acid & $-0.342 ; 0.024$ & & & & & \\
\hline
\end{tabular}

* Linear regression analyses with the psychological variable as dependent variable and one-by-one of the microbiota variables adjusted for gender, age and BMI; $\uparrow$ Stepwise forward linear regression analyses. All the significant variables in the one-by-one analyses were included adjusted for gender, age and BMI. 
Table 4. The significant associations between the functional somatic disorders and the faecal microbiota and SCFA. Regression analyses with the functional somatic disorders as dependent variables.

\begin{tabular}{|c|c|c|c|c|c|c|c|c|}
\hline \multirow{2}{*}{ Microbiota } & \multicolumn{2}{|c|}{ Food Intolerance } & \multicolumn{2}{|c|}{ Musculoskeletal Pain } & \multicolumn{2}{|c|}{ IBS } & \multicolumn{2}{|c|}{ IBS-SSS } \\
\hline & OR; $p$-Value * & OR; $p$-Value $\uparrow$ & B; $p$-Value * & B; $p$-Value $\mathrm{T}$ & OR; $p$-Value * & OR; $p$-Value $T$ & B; $p$-Value * & B; $p$-Value $\uparrow$ \\
\hline ADI & & & & & & & $-10.86 ; 0.010$ & $-10.86 ; 0.010$ \\
\hline Actinomycetales & & & $1.34 ; 0.034$ & & & & & \\
\hline Bifidobacterium spp. & & & $1.22 ; 0.012$ & $0.94 ; 0.039$ & & & & \\
\hline Alistipes & $0.34 ; 0.019$ & $0.34 ; 0.019$ & & & & & $-40.3 ; 0.012$ & \\
\hline Alistipes onderdonkii & $0.52 ; 0.041$ & & & & & & & \\
\hline Bacteroides stercoris & & & $1.25 ; 0.001$ & $1.07 ; 0.004$ & & & & \\
\hline Bacteroides zoogleoformans & & & & & $4.64 ; 0.026$ & $15.55 ; 0.009$ & & \\
\hline Parabacteroides johnsonii & & & & & & & & \\
\hline Parabacteroides spp. & & & & & $2.10 ; 0.037$ & $3.31 ; 0.007$ & & \\
\hline Firmicutes & & & & & $2.30 ; 0.037$ & & & \\
\hline Dia/ister invisus & & & & & $1.95 ; 0.026$ & $2.91 ; 0.008$ & & \\
\hline Eubacterium rectale & & & $-1.63 ; 0.023$ & & & & & \\
\hline Phascolarctobacterium sp. & & & $-1.016 ; 0.030$ & $-0.85 ; 0.049$ & & & & \\
\hline Proteobacteria & & & $-1.026 ; 0.050$ & & & & & \\
\hline Shigella spp. \& Escherichia spp. & & & $-0.71 ; 0.049$ & $-0.75 ; 0.030$ & & & & \\
\hline SCFA total & & & & & $0.967 ; 0.049$ & & & \\
\hline Acetic acid & & & & & $0.935 ; 0.033$ & & & \\
\hline Iso-butyric acid & & & & & $0.080 ; 0.006$ & & & \\
\hline Iso-valeric acid & & & & & $0.213 ; 0.006$ & & & \\
\hline Valeric acid & & & & & $0.217 ; 0.012$ & $0.14 ; 0.003$ & & \\
\hline Iso-capronic acid & & & $-67.1 ; 0.034$ & & & & & \\
\hline Index B & & & & & $0.379 ; 0.005$ & & & \\
\hline Valeric acid Pct & & & & & $0.623 ; 0.029$ & & & \\
\hline Iso-capronic acid Pct & & & $-27.57 ; 0.034$ & & & & & \\
\hline Propionic acid Pct & & & & & $1.14 ; 0.021$ & & & \\
\hline
\end{tabular}

forward linear and logistic regression analyses. All the significant variables in the one-by-one analyses were included adjusted for gender, age and BMI. 


\section{Discussion}

The study demonstrated the numerous significant associations between the faecal microbiota's composition and function and the psychobiological disorders that are challenging to interpret. There is no simple and straightforward explanation and understanding of the gut-brain pathway. The numerous associations indicate complex connections that follow several pathways that are dependent on the trigger and psychobiological disorder.

\subsection{Associations between the Faecal Microbial Composition and Psychobiological Disorders}

A connection between the faecal microbiota's composition and function and psychological disorders seems to be established, but it is poorly understood [7,9]. The connection is not explained by one or a few species or genus [8]. The multiple associations that are seen in this study indicate a complex regulation of the gut-brain connection. Neither was the DI, a general marker of microbial imbalance, a suitable predictor of all the psychological disorders. The associations between the microbiota and the psychological disorders varied between the disorders. It is unlikely that the three variables that were measured in this study (WHO-5, HSCL-10, and fatigue) are specifically associated with different microbes. HSCL-10 and fatigue were negatively associated with ADI, i.e., associated with an unfavourable dysbiosis. Dysbiosis indices that are based on a combination of microbes might prove to be the best suited predictors of psychological disorders. Similar microbial abnormalities in psychological and functional somatic disorders, indicating common aetiological factors, have been shown in other studies but they were not demonstrable in the current study [26,27].

Some bacteria, such as Faecalibacterium prausnitzii and Proteobacteria, have attracted particular attention [28-31]. Faecalibacterium prausnitzii was associated with improved well-being (WHO-5) and less mental distress (HSCL-10), supporting the importance of this bacterium. This study did not support previous reports, indicating an association between the phylum Proteobacteria and epithelial dysfunction and risk of disease. Shigella spp. \& Escherichia spp. and Proteobacteria were negatively associated with musculoskeletal pain, but not with other psychobiological disorders.

\subsection{Associations between the Faecal SCFA and Psychobiological Disorders}

Faecal SCFA have been associated with behavioural, psychological and functional somatic disorders and response to treatment $[10,11,13,25,32,33]$. Like the microbial composition, the results are divergent and in part contradictory and non-reproducible. The favourable effects of butyric acid on brain function were not confirmed in the current study in which total SCFA, acetic acid, propionic acid, and butyric acid were negatively associated with well-being [33]. Previous studies have demonstrated higher levels of faecal SCFA in obese as compared to lean subjects [34,35]. However, the "obesogenic" effect of SCFA remains to be investigated [36].The most noteworthy finding was the associations between IBS and low amounts of total SCFA, acetic acid, iso-butyric acid, iso-valeric acid and valeric acid (both total and relative amount), and reduced proteolytic fermentation. Butyrate has shown favourable effects on visceral sensitivity in healthy volunteers [37]. The local effects of SCFA on the gut seem to be more pronounced than the systemic and centrally mediated ones. The proposed ratio proprionic/butyric acid as a biomarker of IBS was not confirmed [25].

\subsection{Faecal Microbial Composition and Obesity}

As expected, and in accordance with other studies with different methods, the prevalence of faecal dysbiosis measured with the commercially available test was high (61\%) [2,3]. Thirty-two out of 39 bacterial groups (82\%) deviated significantly from the producer's reference population. Since diabetes, the use of Metformin and consumption of NNS, which are associated with dysbiosis, were common in the studied population, dysbiosis might have been related to these factors and not to obesity per se [38-41]. Of note, Faecalibacterium prausnitzii, which has been associated with obesity, was significantly reduced [30]. 


\subsection{Faecal SCFA and Obesity}

In subjects with morbid obesity, the relative proportions of six out of eight SCFA (75\%) deviated significantly from the group of healthy volunteers. In particular, the functions of butyric acid have been studied and seem to be contradictory [42]. In this study, the relative amount of butyric acid was high in the subjects with morbid obesity when compared with the healthy volunteers. In mice, butyric acid reduces appetite and food intake via a central appetite regulation and has a positive influence on the energy balance and diet-induced overweight [43]. If these results are transferable to humans, butyrate has a weight-reducing effect. We are not aware of such studies in humans. Our results did not support this effect. Studies have reported other and opposite effects of butyrate, which in part, could be explained by differences in the metabolic background and dosage [33,42,44].

\subsection{Strengths and Limitations}

The study population was representative of subjects with morbid obesity referred for evaluation of bariatric surgery, and was well suited for this study because of the high prevalence of faecal dysbiosis and psychobiological comorbidity.

Out of the 427 associations between the microbiota and psychobiological disorders (microbiota's composition: 41 variables; SCFA: 20 variables; and, psychobiological disorders: seven variables), $41(10 \%)$ were statistically significant. The number is higher than expected to occur by chance (type I error). Significant associations do not mean causality, and type II errors are also likely. In such studies, there are numerous unknown confounders, colliders, and mediators, and the analyses were not adjusted for such factors. Therefore, the results of this and similar studies should be interpreted with caution.

The test used for the microbiota's composition, measuring an undefined dysbiosis index and the relative amount of "only" 39 bacteria at different taxonomic levels might have been inaccurate or incomplete for the purpose of this study. More precise and detailed analytical methods could have given other results.

Since carbohydrates and fibre are major substrates for the microbial SCFA production, the lack of dietary data is another limitation of the study. In subjects with obesity, reduced intake of carbohydrates has been associated with low concentrations of butyrate and butyrate-producing bacteria in faeces [45]. Dietary differences between the subjects with obesity and the healthy volunteers, and not only the differences in BMI, could thus explain the differences in SCFA between the groups. In the gut-brain communication, it is likely that SCFA, which are dependent on the diet, are the mediators of the psychobiological disorders.

The lack of information about the psychobiological disorders in the healthy volunteers, which is a limitation, render analyses of the associations between the faecal markers and psychobiological disorders in this group impossible. The study, therefore, confines itself to a description of the differences in the SCFA profiles between the groups and discusses associations with obesity without mentioning the psychobiological disorders.

Comparisons of the total amount of SCFA, and not only the relative amounts, with the healthy volunteers, could have strengthened the study.

\section{Conclusions}

The current study in subjects with morbid obesity showed a wide range of associations between the faecal microbial markers and psychobiological comorbidity, and thus confirmed the important gut-brain interaction. The study did not clarify simple communication pathways. On the contrary, the study indicated complex and multifactorial relations that often seem contradictory and that need further studies to clarify clinical implications. 
Author Contributions: P.G.F. has been responsible for accomplishing the study in subjects with morbid obesity, for collecting and analysing the data, and drafting the manuscript. J.V. has been responsible for the group of healthy volunteers and the analyses of SCFA. Both authors have contributed to the interpretation of the results and approved the last version.

Funding: This research was funded by Innlandet Hospital Trust, Brumunddal and Norwegian University of Science and Technology, Trondheim; Norway.

Acknowledgments: The authors wish to thank study nurse Anja Byfuglien for conscientious help with the practical work, the bioengineers Gunn Helen Malmstrøm and Jennifer Twistleton Fiennes at Unger-Vetlesen Institute, Lovisenberg Diaconal Hospital, Oslo, Norway, for performing the SCFA analyses, and Genetic Analysis AS, Oslo Norway for performing the bacterial analyses.

Conflicts of Interest: The funders had no role in the design of the study; in the collection, analyses, or interpretation of the data; in the writing of the manuscript, and in the decision to publish the results.

$\begin{array}{ll}\text { Abbreviations } \\ \text { MO } & \text { Morbid Obesity } \\ \text { SCFA } & \text { Short Chain Fatty Acids } \\ \text { BMI } & \text { Body Mass Index } \\ \text { HV } & \text { Healthy Volunteers } \\ \text { DI } & \text { Dysbiosis Index } \\ \text { ADI } & \text { Alternative Dysbiosis Index } \\ \text { NNS } & \text { Non-nutritive sweeteners } \\ \text { OR } & \text { Odds Ratio } \\ \text { B } & \text { Unstandardized coefficient in the linear regression analyses } \\ \text { WHO-5 } & \text { WHO Well-being index } \\ \text { HSCL-10 } & \text { Hopkin Symptom Checklist 10 } \\ \text { IBS } & \text { Irritable Bowel Syndrome } \\ \text { IBS-SSS } & \text { Irritable Bowel Severity Scoring System }\end{array}$

\section{References}

1. WHO Fact Sheet N 311, Obesity and Overweight. Updated June 2016. Available online: http:/ / www.who. int/mediacentre/factsheets/fs311/en/ (accessed on 10 September 2018).

2. Bouter, K.E.; van Raalte, D.H.; Groen, A.K.; Nieuwdorp, M. Role of the Gut Microbiome in the Pathogenesis of Obesity and Obesity-Related Metabolic Dysfunction. Gastroenterology 2017, 152, 1671-1678. [CrossRef] [PubMed]

3. Gao, R.; Zhu, C.; Li, H.; Yin, M.; Pan, C.; Huang, L.; Kong, C.; Wang, X.; Zhang, Y.; Qu, S.; et al. Dysbiosis Signatures of Gut Microbiota Along the Sequence from Healthy, Young Patients to Those with Overweight and Obesity. Obesity (Silver Spring) 2018, 26, 351-361. [CrossRef] [PubMed]

4. Zhang, X.; Shen, D.; Fang, Z.; Jie, Z.; Qiu, X.; Zhang, C.; Chen, Y.; Ji, L. Human gut microbiota changes reveal the progression of glucose intolerance. PLoS ONE 2013, 8, e71108. [CrossRef] [PubMed]

5. Zhuang, X.; Xiong, L.; Li, L.; Li, M.; Chen, M. Alterations of gut microbiota in patients with irritable bowel syndrome: A systematic review and meta-analysis. J. Gastroenterol. Hepatol. 2017, 32, 28-38. [CrossRef] [PubMed]

6. Bhattarai, Y.; Muniz Pedrogo, D.A.; Kashyap, P.C. Irritable bowel syndrome: A gut microbiota-related disorder? Am. J. Physiol. Gastrointest. Liver Physiol. 2017, 312, G52-G62. [CrossRef] [PubMed]

7. Moser, G.; Fournier, C.; Peter, J. Intestinal microbiome-gut-brain axis and irritable bowel syndrome. Wien. Med. Wochenschr. 2018, 168, 62-66. [CrossRef] [PubMed]

8. Naseribafrouei, A.; Hestad, K.; Avershina, E.; Sekelja, M.; Linlokken, A.; Wilson, R.; Rudi, K. Correlation between the human fecal microbiota and depression. Neurogastroenterol. Motil. 2014, 26, 1155-1162. [CrossRef]

9. Cenit, M.C.; Sanz, Y.; Codoner-Franch, P. Influence of gut microbiota on neuropsychiatric disorders. World J. Gastroenterol. 2017, 23, 5486-5498. [CrossRef] 
10. Gill, P.A.; van Zelm, M.C.; Muir, J.G.; Gibson, P.R. Review article: Short chain fatty acids as potential therapeutic agents in human gastrointestinal and inflammatory disorders. Aliment. Pharmacol. Ther. 2018, 48, 15-34. [CrossRef]

11. Szczesniak, O.; Hestad, K.; Hanssen, J.F.; Rudi, K. Isovaleric acid in stool correlates with human depression. Nutr. Neurosci. 2015, 19, 279-283. [CrossRef]

12. Casen, C.; Vebo, H.C.; Sekelja, M.; Hegge, F.T.; Karlsson, M.K.; Ciemniejewska, E.; Dzankovic, S.; Froyland, C.; Nestestog, R.; Engstrand, L.; et al. Deviations in human gut microbiota: A novel diagnostic test for determining dysbiosis in patients with IBS or IBD. Aliment. Pharmacol. Ther. 2015, 42, 71-83. [CrossRef] [PubMed]

13. Valeur, J.; Morken, M.H.; Norin, E.; Midtvedt, T.; Berstad, A. Intestinal fermentation in patients with self-reported food hypersensitivity: Painful, but protective? Clin. Exp. Gastroenterol. 2010, 3, 65-70. [CrossRef] [PubMed]

14. The Norwegian Food Composition Table. Available online: http:/ /www.matvaretabellen.no/?language=en (accessed on 10 September 2018).

15. Topp, C.W.; Ostergaard, S.D.; Sondergaard, S.; Bech, P. The WHO-5 Well-Being Index: A systematic review of the literature. Psychother. Psychosom. 2015, 84, 167-176. [CrossRef] [PubMed]

16. Søgaard, A.J.; Bjelland, I.; Tell, G.S.; Røysamb, E. A comparison of the CONOR Mental Health Index to the HSCL-10 and HADS. Nor. Epidemiol. 2003, 13, 279-284.

17. Lerdal, A.; Wahl, A.; Rustoen, T.; Hanestad, B.R.; Moum, T. Fatigue in the general population: A translation and test of the psychometric properties of the Norwegian version of the fatigue severity scale. Scand. J. Public Health 2005, 33, 123-130. [CrossRef] [PubMed]

18. Longstreth, G.F.; Thompson, W.G.; Chey, W.D.; Houghton, L.A.; Mearin, F.; Spiller, R.C. Functional bowel disorders. Gastroenterology 2006, 130, 1480-1491. [CrossRef] [PubMed]

19. Francis, C.Y.; Morris, J.; Whorwell, P.J. The irritable bowel severity scoring system: A simple method of monitoring irritable bowel syndrome and its progress. Aliment. Pharmacol. Ther. 1997, 11, 395-402. [CrossRef] [PubMed]

20. Genetic Analysis AS. GAMap TM Dysbiosis Test. Available online: http://www.genetic-analysis.com/ patent (accessed on 10 September 2018).

21. Farup, P.G.; Kvehaugen, A.S.; Aasbrenn, M. Could a test discriminate between the "good" and the "bad" fecal dysbiosis? A study in subjects with morbid obesity. Obes. Facts 2018, 11, 112-113.

22. Zijlstra, J.B.; Beukema, J.; Wolthers, B.G.; Byrne, B.M.; Groen, A.; Dankert, J. Pretreatment methods prior to gaschromatographic analysis of volatile fatty acids from faecal samples. Clin. Chim. Acta 1977, 78, 243-250. [CrossRef]

23. Hoverstad, T.; Bjorneklett, A.; Midtvedt, T.; Fausa, O.; Bohmer, T. Short-chain fatty acids in the proximal gastrointestinal tract of healthy subjects. Scand. J. Gastroenterol. 1984, 19, 1053-1058. [PubMed]

24. Tjellstrom, B.; Hogberg, L.; Stenhammar, L.; Magnusson, K.E.; Midtvedt, T.; Norin, E.; Sundqvist, T. Effect of exclusive enteral nutrition on gut microflora function in children with Crohn's disease. Scand. J. Gastroenterol. 2012, 47, 1454-1459. [CrossRef] [PubMed]

25. Farup, P.G.; Rudi, K.; Hestad, K. Faecal short-chain fatty acids-A diagnostic biomarker for irritable bowel syndrome? BMC Gastroenterol. 2016, 16, 51. [CrossRef] [PubMed]

26. Liu, Y.; Zhang, L.; Wang, X.; Wang, Z.; Zhang, J.; Jiang, R.; Wang, X.; Wang, K.; Liu, Z.; Xia, Z.; et al. Similar Fecal Microbiota Signatures in Patients With Diarrhea-Predominant Irritable Bowel Syndrome and Patients With Depression. Clin. Gastroenterol. Hepatol. 2016, 14, 1602-1611. [CrossRef] [PubMed]

27. Sundin, J.; Rangel, I.; Fuentes, S.; Heikamp-de Jong, I.; Hultgren-Hornquist, E.; de Vos, W.M.; Brummer, R.J. Altered faecal and mucosal microbial composition in post-infectious irritable bowel syndrome patients correlates with mucosal lymphocyte phenotypes and psychological distress. Aliment. Pharmacol. Ther. 2015, 41, 342-351. [CrossRef] [PubMed]

28. Shin, N.R.; Whon, T.W.; Bae, J.W. Proteobacteria: Microbial signature of dysbiosis in gut microbiota. Trends Biotechnol. 2015, 33, 496-503. [CrossRef] [PubMed]

29. Litvak, Y.; Byndloss, M.X.; Tsolis, R.M.; Baumler, A.J. Dysbiotic Proteobacteria expansion: A microbial signature of epithelial dysfunction. Curr. Opin. Microbiol. 2017, 39, 1-6. [CrossRef] [PubMed] 
30. Feng, J.; Tang, H.; Li, M.; Pang, X.; Wang, L.; Zhang, M.; Zhao, Y.; Zhang, X.; Shen, J. The abundance of fecal Faecalibacterium prausnitzii in relation to obesity and gender in Chinese adults. Arch. Microbiol. 2014, 196, 73-77. [CrossRef] [PubMed]

31. Ferreira-Halder, C.V.; Faria, A.V.S.; Andrade, S.S. Action and function of Faecalibacterium prausnitzii in health and disease. Best Pract. Res. Clin. Gastroenterol. 2017, 31, 643-648. [CrossRef] [PubMed]

32. Tana, C.; Umesaki, Y.; Imaoka, A.; Handa, T.; Kanazawa, M.; Fukudo, S. Altered profiles of intestinal microbiota and organic acids may be the origin of symptoms in irritable bowel syndrome. Neurogastroenterol. Motil. 2010, 22, 512-515. [CrossRef] [PubMed]

33. Stilling, R.M.; van de Wouw, M.; Clarke, G.; Stanton, C.; Dinan, T.G.; Cryan, J.F. The neuropharmacology of butyrate: The bread and butter of the microbiota-gut-brain axis? Neurochem. Int. 2016, 99, 110-132. [CrossRef] [PubMed]

34. Schwiertz, A.; Taras, D.; Schafer, K.; Beijer, S.; Bos, N.A.; Donus, C.; Hardt, P.D. Microbiota and SCFA in lean and overweight healthy subjects. Obesity (Silver Spring) 2010, 18, 190-195. [CrossRef] [PubMed]

35. Rahat-Rozenbloom, S.; Fernandes, J.; Gloor, G.B.; Wolever, T.M. Evidence for greater production of colonic short-chain fatty acids in overweight than lean humans. Int. J. Obes. (Lond.) 2014, 38, 1525-1531. [CrossRef] [PubMed]

36. Dugas, L.R.; Lie, L.; Plange-Rhule, J.; Bedu-Addo, K.; Bovet, P.; Lambert, E.V.; Forrester, T.E.; Luke, A.; Gilbert, J.A.; Layden, B.T. Gut microbiota, short chain fatty acids, and obesity across the epidemiologic transition: The METS-Microbiome study protocol. BMC Public Health 2018, 18, 978. [CrossRef] [PubMed]

37. Vanhoutvin, S.A.; Troost, F.J.; Kilkens, T.O.; Lindsey, P.J.; Hamer, H.M.; Jonkers, D.M.; Venema, K.; Brummer, R.J. The effects of butyrate enemas on visceral perception in healthy volunteers. Neurogastroenterol. Motil. 2009, 21, 952-e76. [CrossRef] [PubMed]

38. Montandon, S.A.; Jornayvaz, F.R. Effects of Antidiabetic Drugs on Gut Microbiota Composition. Genes (Basel) 2017, 8, 250. [CrossRef]

39. Wu, H.; Esteve, E.; Tremaroli, V.; Khan, M.T.; Caesar, R.; Manneras-Holm, L.; Stahlman, M.; Olsson, L.M.; Serino, M.; Planas-Felix, M.; et al. Metformin alters the gut microbiome of individuals with treatment-naive type 2 diabetes, contributing to the therapeutic effects of the drug. Nat. Med. 2017, 23, 850-858. [CrossRef] [PubMed]

40. Suez, J.; Korem, T.; Zilberman-Schapira, G.; Segal, E.; Elinav, E. Non-caloric artificial sweeteners and the microbiome: Findings and challenges. Gut Microbes 2015, 6, 149-155. [CrossRef] [PubMed]

41. Sohail, M.U.; Althani, A.; Anwar, H.; Rizzi, R.; Marei, H.E. Role of the Gastrointestinal Tract Microbiome in the Pathophysiology of Diabetes Mellitus. J. Diabetes Res. 2017, 2017, 9631435. [CrossRef] [PubMed]

42. Kannampalli, P.; Shaker, R.; Sengupta, J.N. Colonic butyrate-algesic or analgesic? Neurogastroenterol. Motil. 2011, 23, 975-979. [CrossRef] [PubMed]

43. Li, Z.; Yi, C.X.; Katiraei, S.; Kooijman, S.; Zhou, E.; Chung, C.K.; Gao, Y.; van den Heuvel, J.K.; Meijer, O.C.; Berbee, J.F.P.; et al. Butyrate reduces appetite and activates brown adipose tissue via the gut-brain neural circuit. Gut 2018, 67, 1269-1279. [CrossRef] [PubMed]

44. Bouter, K.; Bakker, G.J.; Levin, E.; Hartstra, A.V.; Kootte, R.S.; Udayappan, S.D.; Katiraei, S.; Bahler, L.; Gilijamse, P.W.; Tremaroli, V.; et al. Differential metabolic effects of oral butyrate treatment in lean versus metabolic syndrome subjects. Clin. Transl. Gastroenterol. 2018, 9, 155. [CrossRef] [PubMed]

45. Duncan, S.H.; Belenguer, A.; Holtrop, G.; Johnstone, A.M.; Flint, H.J.; Lobley, G.E. Reduced dietary intake of carbohydrates by obese subjects results in decreased concentrations of butyrate and butyrate-producing bacteria in feces. Appl. Environ. Microbiol. 2007, 73, 1073-1078. [CrossRef] [PubMed]

(C) 2018 by the authors. Licensee MDPI, Basel, Switzerland. This article is an open access article distributed under the terms and conditions of the Creative Commons Attribution (CC BY) license (http://creativecommons.org/licenses/by/4.0/). 